\section{Disturbance of sensation after mastectomy}

Clinicians may dismiss disturbance of sensation after mastectomy in the follow up of patients with breast cancer, but symptoms such as numbness of the upper arm and phantom breast are a common cause of anxiety for these women, ${ }^{1}$ who have often received inadequate preoperative counselling. ${ }^{2}$ We have therefore studied the nature and prevalence of postmastectomy symptoms and their relation to disease staging.

\section{Patients, methods, and results}

Eighty two patients (age range 33-97) who had undergone unilateral simple mastectomy and axillary node sampling with a single transverse incision were interviewed by either RD or CWOW during attendance at a general surgical follow up clinic. A form was completed for each patient, which recorded age, date of mastectomy, disease stage at interview (Manchester classification), postoperative radiotherapy, and whether cancer had recurred. Local recurrence was diagnosed histologically, but chest radiology and skeletal scintigraphy were performed at the clinician's discretion. Patients were designated "symptomatic" if they admitted to experiencing phantom sensations of the breast or nipple (phantom symptoms) or pain and altered sensation around the mastectomy scar, chest wall, or ipsilateral arm (non-phantom symptoms). Patients denying these specific symptoms were grouped as "asymptomatic." Results were analysed with Student's $t$ test.

The $54(66 \%)$ patients who were symptomatic were younger than the 28 asymptomatic patients (mean age (SD) $58.5(11.6) v 64 \cdot 1$ (13.7)), but this difference was not statistically significant $(t=1.93 ; \mathrm{p}<0.1)$. The interval between mastectomy and interview was similar in both groups (symptomatic $2 \cdot 5(2 \cdot 1)$ years; asymptomatic $2 \cdot 7(2 \cdot 3)$ years). Twenty five patients had experienced phantom sensation, which was related to the breast in 12 patients, the nipple in two patients, and both the breast and nipple in 11 patients. Phantom breast pain was described by only six patients. Numbness or pain of the medial aspect of the upper arm was described by 19 patients, and pain or irritation around the scar was described by five. Symptoms also included shoulder pain (one patient) and chest pain (two patients). There was no significant difference in the mean age of patients who described phantom $(58.2$ (11.3)) and non-phantom (58.8 (11.9)) symptoms, but the percentage of those with phantom symptoms decreased with increasing age at mastectomy (43\% of patients aged less than 50 , compared with $16 \%$ of patients aged over 69). There was no difference in the distribution of symptomatic and nonsymptomatic patients according to disease stage (see table).

Distribution of symptomatic and non-symptomatic postmastectomy patients according to disease stage at interview

\begin{tabular}{|c|c|c|c|c|c|c|c|c|c|}
\hline \multirow[b]{3}{*}{ Groups } & \multirow{3}{*}{$\begin{array}{c}\text { No of } \\
\text { patients }\end{array}$} & \multicolumn{8}{|c|}{ Disease stage } \\
\hline & & \multicolumn{2}{|c|}{ I } & \multicolumn{2}{|c|}{ II } & \multicolumn{2}{|c|}{ III } & \multicolumn{2}{|c|}{ IV } \\
\hline & & No & $(\%)$ & No & $(\%)$ & No & $(\%)$ & No & $(\%)$ \\
\hline $\begin{array}{l}\text { Symptomatic } \\
\text { Phantom } \\
\text { Non-phantom } \\
\text { Both } \\
\text { Asymptomatic }\end{array}$ & $\begin{array}{l}54 \\
13 \\
29 \\
12 \\
28\end{array}$ & $\begin{array}{l}39 \\
10 \\
20 \\
10 \\
20\end{array}$ & $\begin{array}{l}72 \\
77 \\
69 \\
83 \\
71\end{array}$ & $\begin{array}{r}12 \\
2 \\
8 \\
2 \\
7\end{array}$ & $\begin{array}{l}22 \\
15 \\
28 \\
17 \\
25\end{array}$ & $\begin{array}{l}0 \\
0 \\
0 \\
0 \\
1\end{array}$ & 3.6 & $\begin{array}{l}3 \\
1 \\
1 \\
0 \\
0\end{array}$ & $\begin{array}{l}6 \\
8 \\
4\end{array}$ \\
\hline
\end{tabular}

\section{Comment}

Mastectomy is associated with undoubted morbidity, which includes not only the complications of surgery but also the common psychological sequelae to this disfiguring operation. In addition, we have found that over $60 \%$ of patients described symptoms which arose from disturbed somatic sensation. Non-phantom symptoms were described by half the patients and consisted predominantly of pain or numbness of the upper arm. Sensory disturbances in the arm after mastectomy probably result from damage to the intercostobrachial nerve, although the carpal tunnel syndrome and brachial plexus entrapment have been reported in association with lymphoedema. ${ }^{3}$ Half of the patients had experienced phantom breast sensaticns, which were rarely painful and affected the entire breast more often than the nipple alone. Phantoms occurred more commonly in younger patients, and previous studies have shown that they occur typically in premenopausal women who have adjusted poorly to mastectomy and who often have an underlying psychological disturbance. ${ }^{14}$ We found no evidence to suggest that either phantom or non-phantom symptoms occurred more com- monly in advanced disease, although a systematic search for occult dissemination was not undertaken in every patient.

These common symptoms, particularly phantoms, may cause considerable anxiety for patients, who rarely mention them to their medical attendants. ${ }^{1}$ It would seem advisable to include their description in the preoperative counselling of women undergoing mastectomy, who should be reassured that they do not indicate a late stage of the disease.

1 Jamison K, Wellisch DK, Katz RL, Pasnau RO. Phantom breast syndrome. Arch Surg 1979;114:93-5.

${ }^{2}$ Feeley TM, Peel ALG, Devlin HB. Mastectomy and its consequences. Br Med f $1982 ; 284: 1246$.

${ }^{3}$ Ganel A, Engel J, Sela M, Brookes $M$. Nerve entrapment associated with post-mastectomy lymphedema. Cancer $1979 ; 44: 2254-9$.

4 Weinstein S, Vetter RJ, Sersen EA. Phantoms following breast amputation. Neuropsychol 1970;8:185-97.

(Accepted 28 February 1984)

Department of Surgery, Worcester Royal Infirmary, Worcester WR5 1HN

R DOWNING, BSC, FRCS, registrar

C W O WINDSOR, CHM, FRCS, consultant

Correspondence to: $\mathrm{Mr} \mathrm{CW} \mathrm{O}$ Windsor.

\section{Asthma inhalation devices: what do we know?}

The correct technique for using aerosols has recently received critical appraisal ${ }^{1}$ and there are now several devices less prone to errors of technique. Correct instruction is often emphasised ${ }^{2}$ and is valuable, ${ }^{3}$ but there have only been two studies of the competence of staff to teach. ${ }^{45}$

\section{Subjects, methods, and results}

Twenty three doctors and 20 nurses from the medical and paediatric departments of two local hospitals were questioned. The doctors were of senior house officer grade or above and included all six consultants. Nineteen local general practitioners from six practices were also questioned. They were asked to demonstrate the use of an aerosol inhaler, a Spinhaler, and a Rotahaler. For each device the demonstrator scored one mark if some medication would be delivered by the method he showed and a second for showing refinements of technique. Thus the extra mark was awarded for the inhaler for shaking the aerosol before use and breath holding after use; for the Spinhaler if some indication was given of the force of inspiration needed; and for the Kotahaler for loading with the device vertical to ensure that the powder entered the clear portion of the capsule and rotation with the device horizontal to avoid spillage. Thus a maximum of six points were available. The doctors were then asked about the degree of instruction given - for example, verbal instruction only or a full demonstration.

The general practitioners scored significantly better than all the other groups except the paediatric nurses ( $p<0.05$ with Student's $t$ test) (see table). The general practitioners also taught and checked technique more often ( $p<0.05$ using the $\chi^{2}$ test), whereas the hospital doctors were more inclined to delegate. Twenty doctors (of whom only three were general practitioners) sometimes delegated tuition to other staff, usually to nurses. Senior hospital doctors also delegated to their juniors, and six doctors mentioned physiotherapists (though the local physiotherapists do not see teaching of aerosol technique as one of their roles). Five general practitioners claimed that they always checked technique and eight usually, whereas no hospital doctors claimed that they always checked technique and only eight stated that they usually did so.

\section{Comment}

Most striking was the poor level of scoring. Even with the aerosol inhaler only $36 \%$ of the doctors and $30 \%$ of the nurses remembered two important refinements. These figures correspond well with Frew and MacFarlane's figures of $28 \%$ and $22 \%$ respectively. ${ }^{5}$ With few exceptions those who scored two marks with the aerosol also scored well with the Rotahaler and the Spinhaler. Eight people 